\title{
Malpractices and Path of Reform Concerning Psychiatric Identification in China-Taking the "Heading-cutting Case" Committed by Hu as an Entry Point
}

\author{
Li Zhenjie*, Tang Yiliang \\ Department of Law, Southwest University of Political Science \& Law, Chongqing, China
}

Email address:

keith@hiwayslaw.com (Li Zhenjie), 767093410@qq.com (Tang Yiliang)

${ }^{*}$ Corresponding author

\section{To cite this article:}

Li Zhenjie, Tang Yiliang. Malpractices and Path of Reform Concerning Psychiatric Identification in China-Taking the "Heading-cutting Case" Committed by Hu as an Entry Point. International Journal of Law and Society. Vol. 1, No. 3, 2018, pp. 108-114.

doi: $10.11648 /$ j.ijls.20180103.12

Received: September 10, 2018; Accepted: October 12, 2018; Published: November 5, 2018

\begin{abstract}
Recent years have witnessed a frequent increase in the number of crimes committed by the mentally ill, which accordingly leads to more cases that psychiatric perpetrators were exempted from liability, exemplified by the "head-cutting case" committed by $\mathrm{Hu}$ in Wuchang. However, exempting the mentally ill from criminal liability is only an exception as for imposing liabilities on criminal subjects. In judicial practice, it should be limited in use as much as possible to avoid instability occurring in the criminal law system due to the expansion of its application. At present, there are still many defects in the regulations on the mentally ill in China. On the one hand, it is difficult to provide a clear and practical definition of the exemption for the mentally ill. On the other hand, a series of problems have arisen since the public would hold doubts about the exemption for some defendants. In order to prevent "false" psychiatric identification and guarantee the effectiveness of the exemption exclusively to the mentally ill, it is necessary to analyze the value basis of exemption for the mentally ill and deconstruct some standards of psychiatric identification and related legal provisions. It should be further realized that the current psychiatric identification mainly has three defects including vague legal provisions, varied standards of identification, and improper entity in charge of initiating the identification. Given this, the paper has proposed solutions from four aspects, i.e., clarifying the standards for identifying mental illness, standardizing the criteria for admission of the appraisers, determining appropriate entity for initiating the identification, and severely punishing "false" psychiatric identification.
\end{abstract}

Keywords: Mental Illness, Mandatory Medical Treatment, Judicial Appraisal, Identification Standards

\section{Introduction}

On February 18, 2017, a person surnamed Hu had a quarrel with the owner of a noodle restaurant nearby Wuchang Railway Station in Wuhan. After that, he took a kitchen knife and killed the restaurant owner, whose head was cut off and thrown into a trashcan by $\mathrm{Hu}$. Afterwards, the public has been talking about this wildly, wondering why Hu behaved so cruel. And the case became clearer after the police took control of the suspect in time [1].

It is known that $\mathrm{Hu}$ dropped out of junior high school and left home for work at the age of 16 or 17 . He has been in unstable mental status with extremely violent temper. After the case occurred, Hu's relatives submitted a Disability Certificate issued by the Disabled Persons' Federation in the County to the police for proving that $\mathrm{Hu}$ had "Grade II" "psychiatric" disability and Hu's father was his supervisor. It was hard for the public to accept the conclusion that the suspect was mentally ill because there were too many cases using mental illness to escape legal punishment, and it seems that criminals have taken "mental illness" as a "protective talisman". People could not understand why a ruthless killer cannot be punished accordingly and the victim's family can do nothing about it.

At present, there are still defects in China's provisions on mental illness, which cannot give the public an accurate 
explanation and make it hard to determine whether the suspect is truly a psychiatric patient, so people have doubts about the exemption of some suspects [2]. Faced with the vague definition of mental illness and various consequent problems, it is urgent to come up with a solution to the problem of how to improve relevant provisions on the mentally ill.

\section{Value Basis of Exemption for the Mentally III}

As a general defense to escape criminal liability in China, the exemption for the mentally ill is necessarily based on certain values. At present, opinions vary on the value basis of exemption for the mentally ill, but there are mainly two streams: one is legal paternalism, and the other is the value balance between individual standard and social standard.

\subsection{Legal Paternalism}

"Legal paternalism" is also known as paternalism [3]. According to Legal Philosophy: Encyclopedia, it was originally derived from the Latin word "pater", which means taking care of children like a father. The book also mentions a term as "rational legal paternalism", which mainly indicates that laws can better protect the legitimate rights of legal subjects by limiting the rights and freedoms of other individuals. As for the exemption for the mentally ill, it embodies a kind of legal paternalism as the state sets a restriction on some people with mental illness by mandatory medical treatment or other viable methods for diagnosis and treatment in order to protect the mentally ill and potential victims. Legal paternalism has always advocated the protection of the rights and interests of citizens. This generally includes two connotations. One is to obstruct others from inflicting on ourselves, and the other is to increase others' interests. Legal paternalism is divided into direct paternalism and indirect paternalism based on differences in defined objects. The former is to restrict the freedom of relative beneficiaries. For example, the laws require the beneficiaries to keep a certain status within a certain period of time; the latter is to restrict the freedom of subjects relative to the beneficiaries, requiring the corresponding subjects to stay away from a certain space-time scene for the purpose of being free from the threat of the beneficiaries. China's legal provisions on the mentally ill reflect the direct paternalism and impose constraints on the beneficiaries.

Legal paternalism is an independent legal language for specific purposes. It is affected by the ruling idea while being a basic legal concept that requires individuals to engage in standardized behaviors of regulation. Legal paternalism gives the state the qualification to bind individuals' rights and freedoms in order to safeguard the interests of the society, so that the state can step further into the territory of individuals. However, we should pay heed to the limitations of legal paternalism.

First, it may lead to the lack of moral considerations in the legal rules. When the state interferes too much with the individuals, people would feel uneasy and on the alert. The state prefers to impose what it believes to be good on the individuals, regardless of whether they really need it or not. In many cases, it cannot make people more well-off but deprives them of independence. Second, it may lead to legal provisions that deviate from judicial practice. The legal paternalism basically means good, but its legal restrictions on individual behavior may lead to invalidity of its laws or go against its legislative objectives. For example, the legal provisions on the exemption for the mentally ill in China are based on the principle of carrying out humanitarian spirit and protecting those with mental illness and other vulnerable people. However, due to the imperfect legislative technology and continuous emergence of new situations and new phenomena, someone may "fake" the mentally ill in judicial practice. Therefore, legal paternalism can limit individuals' freedom and rights only if there are sufficient causes.

Taking a further consideration in the legitimacy of such restrictions, it shall be achieved by comparing the rights that the state attempts to maintain with the restricted citizens' rights. It can continue only if the former benefit is greater than the latter. There is a trade-off between power and rights, and the "territory" of rights will shrink with the expansion of power. The appropriate legal paternalism embodied in the legislation is just to prevent the infinite expansion of state power, thereby protecting individuals from self-inflicted harm, so as to promote the pursuit of individual freedom. It is related to the legal paternalism that blends with ethical affection as well as China's classical administrative paternalism that values family ethics. Therefore, we should properly treat the relationship between the two and build the legal paternalism with Chinese characteristics by integrating China's traditional concept with the western legal paternalism. On the basis of absorbing the essence of western legal paternalism, we will adopt a different perspective to interpret the theory of socialist rule of law with Chinese characteristics.

\subsection{Value Balance Between Individual Standard and Social Standard}

The society is made up of individuals, who exist as unique creatures. Marx once said: "The first premise of any human history is undoubtedly the existence of living individuals." [4] As the foundation and central criterion of all free and democratic societies, individual standard can be elaborated from various angles, but since personal value is taken as the priority, we should examine the individual standard from the perspective of values. In this regard, the individual standard is in a high position within an unrestricted field. Although the individual standard values from classical liberalism to modern conservatism have different focuses respectively, they mainly emphasize individual's longing for freedom and interests. Bentham in the period of classical liberalism said that "only personal interests are most important" [6]; Ayn Rand, a modern conservative representative, believed that a state is a collection of individuals, just like other groups, and all interests other than those for citizens are redundant.

The pressure of competition is expanding in modern society. Due to intense working environment and a lack of effective ways to relax, people are subject to an increasing prevalence and 
recurrence rate of mental illness, and attacks by the mentally ill occurred from time to time. For those who are at risk to the society or themselves due to mental illness, they are a small group in the society, and the state must take a central management for them through laws, so as to achieve the unification of individual standard and social standard.

\section{Standards and Regulations for the Identification of Mental Illness}

\subsection{Several Standards for the Definition of Mental Illness}

According to Article 18 of the Criminal Law and Article 284 of the Criminal Procedure Law in China, the mentally ill, i.e., those without criminal capacity, are included as applicable objects of the provisions in both Laws. For determining whether a perpetrator has mental illness or not, medical standards should be taken as the main reference with legal standards as a supplementary.

\subsubsection{Medical Standards}

In the field of psychiatric medicine, the concept of "mental illness" has been widely used for identification. As far as the semantic interpretation is concerned, it is similar to mental diseases or mental disorders. It should be noted that, mental disease refers to the imbalance of the brain's internal functions under the influence of various biological, psychological and social environment factors, resulting in diseases with multiple levels of defects in psychiatric motions related to cognition, emotion, thought and behavior, etc. Mental disorder refers to the confusion of the brain's functions that results in multiple levels of defects in the psychiatric motions related to cognition, emotion, thought and behavior, etc. The psychiatric motion mentioned above is also known as psychological motion. It refers to a series of complex motions as the brain reflects objective things, mainly including: cognition, emotion, thought, etc. [5] By analyzing the above two definitions, it can be seen that the basic meanings expressed by mental disease and mental disorder are roughly the same, but there are still subtle differences between the two. Mental disease basically falls into the category of biology and it contains a specific singularity, while mental disorder encompasses many fields such as biology, psychology and sociology.

In the medical field, mental illness is subject to both broad and narrow theories. The so-called generalized mental illness is a kind of mental disorder mainly featured with clinical manifestations of abnormal mental activities. It shows no obvious difference in meaning compared to mental disease and mental disorder, but mainly differs in the degree of psychiatric problems. For example, schizophrenia, paranoia, etc. are mental disorders of "severe mental illness", while abnormal personality, sexual psychological distortion, etc. are mental disorders of "mild mental illness". [7] Narrow mental illness only includes severe mental disorders. It is based on some theoretical grounds, and means that the mental abnormality has reached a very critical level and continued for a certain period of time, while the brain functions lose balance due to the influence of various internal and external factors, resulting in psychiatric motions related to cognition, emotion, thought and behavior, etc.

\subsubsection{Legal Standards}

Viewing relevant regulations inside and outside China, there are differences between the two major legal systems in terms of the legal standards for the definition of mental illness. The common law system seeks a way of definition from the purpose of criminal law based on psychiatry. This system mainly believes that as long as the ability to recognize or control is lost, it can be recognized as a mental disease. In addition, an "exception" has been made for the category of mental illness, i.e., psychological disorder caused by multiple crimes or violations. Under the circumstance of "exception", there is no need to consider whether the suspect who commits a criminal act is capable of understanding or self-controlling, and the defense for innocence on the grounds of mental illness is not applicable.

The legal standards in the civil law system are slightly different. According to the People's Health Law of the People's Republic of China, mental disorders refer to abnormal psychiatric motions of feelings, emotions and thoughts caused by various problems that make people uncomfortable or unable to adapt to society. The scope of mental disorders is roughly the same as that of mental illnesses. Meanwhile, the civil law system divides "mental diseases" into two categories, i.e., psychiatric loss and psychiatric depletion. The so-called psychiatric loss refers to the lack of ability to distinguish between right and wrong because of psychiatric obstacles, including the consequent incapacity for act. The psychiatric depletion refers to the significant weakening of the recognition and defense ability due to psychiatric obstacles, but not all of them are missing. But if it is the common law system or civil law system, the definition of mental illness falls into the category of generalized mental illness.

\subsection{Relevant Legal Provisions for the Mentally IIl}

\subsubsection{Procedural Level: Mandatory Medical Treatment}

Mandatory medical treatment means involuntary compulsory treatment for citizens, and it is applicable to the mentally ill who commit cruel and harmful crime, for the purpose of protecting the society from damages through mandatory medical treatment. In essence, mandatory medical treatment is a physical measure for criminal cases. It can partly reduce the personal injury done by the mentally ill to other individuals, so as to protect the whole society. The functions of compulsory treatment are undoubtedly "good news" for people with mental illness. There are mainly two functions. One is to protect the general public, that is, the public is less likely to be harmed by the mentally ill if those people are under mandatory treatment. It functions as if the state is protecting the interests of the general public. When there is a conflict between personal rights and social rights, the latter one should be given priority. The second function is to give specific treatment to individuals. The fundamental 
purpose of mandatory treatment is to treat the mentally ill who are potentially harmful to society. By giving specific treatment to each individual, it can help them regain their healthy mind so that they can integrate into society as soon as possible.

The provisions on mandatory medical treatment in the Criminal Procedure Law are too "general" and there should be some specific rules for implementation as a supplementary. At present, there are six local regulations for mandatory medical treatment for the mentally ill, i.e., Beijing Mental Health Regulations, Shanghai Mental Health Regulations, Hangzhou Mental Health Regulations, Ningbo Mental Health Regulations, and Wuxi Mental Health Regulations. For example, Article 32 of the Wuhan Mental Health Regulations states that if a mentally ill or suspected mentally ill person has posed serious dangers to public safety and personal safety, the public security authority at the place where the incident occurs shall entrust a qualified institution to conduct a psychiatric identification on the person according to the law. If it is determined that the person cannot recognize or control his/her behavior in the incident, the person shall be sent to a designated mental health medical institution to receive mandatory medical treatment, and meanwhile his/her guardian should be notified in time. In this Article, the extensions such as "severely endangering public safety" and "personal safety of others" are too general and the regulations are too vague, which is not conducive to the specific operations in practice.

\subsubsection{Practical Level: Exemption from Criminal Liability}

Article 18 of the Criminal Law stipulates that the mentally ill are not criminally liable if it is confirmed by legal procedures that they cannot recognize or control their behavior when causing harm. Indirect mentally ill persons who commit crimes while being psychiatrically normal shall be criminally liable. Those who have not completely lost the ability of recognizing or controlling their behavior when committing the crime shall be criminally liable, but they may be given a lighter or mitigated punishment. According to the provisions of the Law, persons suffering from mental illness, such as depression and hypochondria, shall bear criminal liabilities for causing dangers at the moment when they can recognize and control their own behavior, but they are not criminally responsible if they cannot recognize and control their behavior. As far as the current social environment is concerned, when it is known that a criminal suspect is psychiatrically ill, we cannot arbitrarily convince that the suspect will not be held liable until it is confirmed by certain identification procedures. The reason for this is to protect the people who truly have mental disorders and to prevent "the fake mentally ill" from evading the law. In addition, criminal capacity refers to the ability of a person to distinguish the nature and outcome of his or her behavior with a control, which is a necessary condition for defining a criminal subject. Natural people who are mentally normal have normal psychic activities and can correctly understand and control their behavior, that is, they can know what they are doing. But for those psychiatrically ill, they can't control their behavior during the illness or realize the harmful consequences of their behavior. If we critically require the mentally ill to bear the same liability as a normal person at this time, it is obviously unscientific and not punitive, which is adverse to achieve the goal of general prevention.

\section{Malpractices of Psychiatric Identification in China}

China has made certain provisions for mental illness by laws, but there are malpractices and loopholes mainly in the following three aspects.

\subsection{Ambiguous Legal Provisions}

China has a wide variety of criteria for the definition of mental illness, but just because there are various criteria, it is easy for us to get lost in the direction and do not know which criterion can be most accurately applied to distinguish a specific psychiatric patient. As for the mandatory medical treatment for the mentally ill, it is clearly stated by laws that the mandatory medical procedures can be initiated only when necessary. However, it is difficult to define when is "necessary". Article 284 of the Criminal Procedure Law stipulates the condition of "there is a possibility of continuing to harm the society" as the premise of initiating the mandatory medical treatment, but it is an open expression, and there are no clear rules for making a judgment of what situation is within this scope of condition, which entity can make the evaluation, and what are the guidelines for the evaluation. In this way, it undoubtedly leaves the judge a great discretion[8]. In the process of mandatory medical treatment, if the case-handling authorities cannot adopt this premise well, "disuse it when necessary but abuse it when needless", it will cause damage to the function of mandatory medical treatment. Article 288 of the Criminal Procedure Law stipulates that: "For those having no danger to others and it is not necessary to further receive mandatory medical treatment, a report should be made and promptly submitted to the corresponding court for an approval to dismiss the treatment". The "approval" here is an inappropriate wording because it sounds like an administrative order. According to the relevant provisions of the Criminal Procedure Law and the essential nature of judicial power, the types of rulings made by the court mainly include judgments, verdicts, and decisions, and "approval" is not a form of court ruling.

\subsection{Different Identification Standards}

Psychiatry began in the 21 st century, so it is still a new thing in the stage of underdevelopment, which is reflected in the identification of mental illness since there is still no specific chemical or physical standards for evaluation and no uniform identification standards. In each diagnosis and treatment system, the difference in version results in the differentiation of diagnostic criteria [9]. In the absence of uniform identification standards, the psychiatric identification relies entirely on the appraisers' expertise and clinical experience. It 
means that, in the process of judicial appraisal, the appraisers cannot get rid of the interference from subjective and objective conditions in external environment, which will affect their conclusions of identification. Besides, the appraisers may lack a serious and prudent attitude when collecting the materials needed for identification, or they may be subject to a limited level, leading to insufficient materials and devious results, so that defective reports are increased accordingly and result in false identification. In addition, because the identification standards are different, the identification reports are affected by many subjective and objective factors [10]. In practice, it also occurs from time to time that different appraisers give different results for the same object of identification, and that gives space for power "rent-seeking" [11]. Some appraisers cannot resist the temptation of interest, and give false identification results to send suspects with mental illness to prison or execution ground, or exempt those without mental illness from criminal liability.

\subsection{Improper Entity in Charge of Initiating the Identification}

According to relevant provisions of the Criminal Procedure $L a w$, there is a lack of flexibility in determining the entity in charge of initiating the psychiatric identification, which increases the power (interest) imbalance between the prosecution and the defense. According to the Criminal Procedure Law and related judicial interpretations, the identification can only be activated by the entity in charge of each phase according to their respective functions in different stages of the proceedings, while the suspects and defendants cannot apply for the identification, thus leading to many problems. First of all, as the sole subject who can activate the judicial appraisal procedure for mental illness, the judicial personnel may make a wrong decision on whether the criminal suspect or the defendant needs to take the psychiatric identification due to the limitations of their own profession [12]. Since most of the judicial personnel are only legal experts, they do not have professional knowledge on the initial identification of mental illness, but can only rely on their own perception. Secondly, in the process of case investigation and prosecution, the investigative and procuratorial authorities tend to fight crime with the concept of "incriminating" to drive the accusation, so they are not keen in proving the suspect or the accused innocent or less punishable. Thirdly, China's criminal litigation in the trial stage is similar to a progressive flow process. the authorities in charge of investigation, prosecution and adjudication basically "cooperate with each other" as a large "community of interests". As a member of the "community", the court is naturally reluctant to exempt those accused of guilty from criminal liability by means of psychiatric identification.

In addition, it should be emphasized that, currently the We-media is highly developed, so the "trial" and high pressure of public opinions are what the judges have to consider. Taking the case of Qiu Xinghua as an example, in the face of such a flood of public opinions, it requires the judges to have a lot of courage to withstand the pressure from public opinion in order to initiate the psychiatric identification [13]. Considering the underdevelopment of psychiatric identification in the current stage, if Qiu Xinghua is identified as a mentally ill person who cannot recognize or control his behavior, the judge shall make a decision on mandatory medical treatment, which means that the "killing madman" will return to society. So in the face of public opinion, the judges tend to keep silent, rather than choose to initiate a psychiatric identification procedure that is beneficial to the accused.

\section{Path of Reform for Psychiatric Identification in China}

As mentioned above, in view of the malpractices and various problems in the identification of mental illness in China, it is necessary to propose a solution by making a combination of legislation and practice, thereby providing a useful reference for the reform of psychiatric identification.

\subsection{Clarifying the Standards for Identifying Mental illness}

There are many standards for the definition of mental illness, but those provisions are too general and vague that they need to be clarified through judicial interpretation. By doing this it cannot only protect the human rights, but also prevent appraisers from abusing their power. Opinions should be widely collected in society and the industry through trial and error for the standards of psychiatric identification, with full consideration of the operability in practice. At present, many international medical materials and diagnostic guidelines have adopted the concept of "mental disorder", such as the Classification of Mental and Behavioral Disorder: Clinical Description and Behavioral Guidelines (ICD), and the Diagnostic and Statistical Manual of Mental Disorder (DSM). Mental disorder contains many concepts, such as mental disease, psychiatric retardation, personality disorder, and dependence on materials. Therefore, the author believes that China's standards of psychiatric identification should cater to the medical development by replacing the term mental illness with the term "mental disorder". In addition, in order to further broaden the cause of human rights protection in China and reduce the failure of judicial authorities to initiate the treatment when necessary, we should also expand the target of mandatory medical treatment in China. For example, in the Criminal Codes of Japan, Switzerland, Austria and other countries, the object of mandatory medical treatment includes not only those without criminal capability, but also those with incomplete capability [8]. The object of mandatory medical treatment in the Criminal Codes of Germany and Mongolia also include the mentally ill who are incapable of accepting a trial or bearing a punishment.

\subsection{Standardizing the Criteria for Admission of the Appraisers}

In practice, the reason why the identification conclusions 
vary a lot from time to time is both related to the identification standards and the quality of the appraisers, so we must strictly control the criteria for admission of the appraisers. Unlike general clinical diagnosis, psychiatric identification is a specialized technique. In order to achieve "consistent" identification results, effort should be made as follows. First of all, the appraisers must be proficient in psychiatry with certain technical titles, and have undergone comprehensive and systematic learning about mental illness. For those with merely clinical experience, they can only participate in the identification process as a technical consultant. Second, the appraisers must have certain legal knowledge. This is because the judicial appraisal will eventually return to the judicial level, which needs to be supplemented by relevant legal knowledge. The appraisers need to determine whether the perpetrator has reached the level of mental disorder as stipulated by the criminal law based on the means, tools and methods used by the perpetrator to commit crime. Thirdly, in order to ensure that the appraisers maintain an objective and fair attitude in the psychiatric identification, it is necessary to carry out a series of trainings to equip the appraisers with correct morality and attitudes towards money as well as self-discipline to resist the lure of money and power.

\subsection{Determining Appropriate Entity for Initiating Psychiatric Identification}

At present, China's initiation procedure for psychiatric identification appears as an "official monopoly" mode, that is, only judiciary authorities can initiate it based on their functions, while the accused who may be mentally ill has no right for initiation [14]. And judiciary authorities face no legal consequences stipulated by laws for its inaction in this regard, so they are not keen in initiating the psychiatric identification under the traditional litigation concept of "fighting crimes is more important than protecting human rights", so there is a certain kind of randomness involved. The criteria to measure whether the setting of power (interest) is reasonable should be based on whether or the power is "controlled". In order to prevent the arbitrary exercise of public power, the respondent should be given the right to apply for psychiatric identification, that is, "additionally giving the parties, legal representatives, defenders and their close relatives the right to apply for initiating the procedure of psychiatric identification". However, cases of evading criminal liability through the exemption for the mentally ill have occurred from time to time. Therefore, certain requirements shall be imposed on such applications, the submission of which must be supported by enough clues or materials.

\subsection{Severely Punishing "False" Psychiatric Identification}

Considering the hysteresis of legislative procedure, laws cannot "reach every aspect" of all the situations in practice, and some loopholes are bound to occur. It is necessary to increase the punishment on "false" identification of mental illnesses, so as to prevent some people from maliciously utilizing the exemption for "the mentally ill" and escaping from criminal liability by exploiting an advantage of inconsistent identification standards, for instance. Starting from subjective aspects, we should not only punish those who deliberately evade criminal liability through psychiatric identification, but also trace the accountability of those who help to do it. Taking the case of Qiu Xinghua for example, although Qiu Xinghua himself claimed that he was not mentally ill, his wife and relatives believed he was and had repeatedly persuaded the defenders to help them make an application to court [15]. Depending on the degree of caused harm, there could be administrative (such as fines, detention) or criminal (such as perjury) punishments.

\section{Conclusion}

At present, with frequent increase in the crime rate of the mentally ill, people have paid close attention to the problem of such crimes, such as Hu's "head-cutting case" that took place in Wuchang. However, China's Criminal Law, Criminal Procedure Law, Mental Health Law and other related laws on the provisions about crimes committed by the mentally ill are relatively vague or apparently disadvantageous to the mentally ill. On the basis of examining the practices, it is urgent to find out the malpractices and learn from the advanced practices of foreign countries. Firstly, it is advisable to cater to the development of the medical cause and its corresponding protection of human rights, clarify the standards to define mental illness, replace the term "mental illness" with "mental disorder", and appropriately expand the target of mandatory medical treatment in China; secondly, we should standardize the criteria for admission of the appraisers, who should have both psychiatry and legal knowledge. In addition, it is necessary to enhance the sense of responsibility of the appraisers by strengthening their trainings. Thirdly, it is suggested to reasonably set the subjects for initiating psychiatric identification, and include relevant parties, legal representatives, defenders and their close relatives in the scope of initiators by changing the previous single-mode of initiation; and fourthly, we should strictly punish the "false" results of psychiatric identification, and impose administrative or criminal punishment according to the harm level [16], so as to improve relevant provisions on mental illness in China.

\section{References}

[1] Netease News: http://news.163.com/17/0219/18/CDLHLBCD0001875P.html, accessed on May 1, 2017.

[2] Li Naling: Judicial Judgment of "the Mentally Ill" in Criminal Mandatory Medical Treatment, Law Science Magazine, Vol. 8 , 2016, p. 119.

[3] Zhang Wenxian: Research on the Tendency of Methodological Philosophical Thoughts in the Twentieth Century, Law Press, 1996, p. 549. 
[4] Marx: Selected Works of Marx and Engels, People's Publishing House, 1972, p. 125.

[5] [English] Jimmy Bentham: Theory of Legislation, translated by Li Guifang, Chinese People's Public Security University Press (version 2014), p. 65.

[6] Hao Wei: Psychiatry, People's Publishing House, 2001, vol. 1.

[7] Chu Chencheng: The Systematic Defects and Reconstruction of Psychiatric Identification Rules in Criminal Judgment, Research on Rule of Law, Vol. 2, 2018, p. 153.

[8] He Hongqiang: On the System of Criminal Defendants' Ability to Trial in China, Legal Forum, Vol. 5, 2016, p. 146.

[9] Wang Junwei: Review of the Relief Mechanism for China's Mandatory Treatment, Law, 2016, Vol. 12, p. 131.

[10] Sun Hao: The Distribution of Proof Responsibility for Psychiatric Issues in Criminal Proceedings, Law Science Magazine, Vol. 1, 2017, p. 105.

[11] There are data showing that the inconsistency rate between the appraisal opinions in the same case currently in China has reached about $30 \%$. See Ye Shengbin: Introduction to Mandatory Medical Procedures, Political and Legal Forum, Vol. $1,2014$.

[12] Chen Bangda: Empirical Research on Initiating Procedure for Psychiatric Judicial Identification, Law Application, Vol. 23, 2017, p. 63.

[13] Sina.com: "The Killing Maniac" Qiu Xinghua's Mental Illness in Suspense, website:

http://news.sina.com.cn/c/2006-12-13/190611782060.shtml, accessed on May 1, 2017.

[14] Chen Yiwei: On the Abuse and Prevention of Psychiatric Identification Procedures in the Process of Criminal Proceedings, Crime Research, Vol. 6, 2017, p. 102.

[15] Zhang Qinting: Discussion on the Focus Issues about Judicial Identification of the Criminal Liabilities for the Mentally Ill, Chinese Journal of Forensic Sciences, Vol. 6, 2015, p. 47.

[16] He Xiaojun: The Paradox and Solution of Psychiatric Identification, Science of Evidence Law, Vol. 1, 2016, p. 98. 